\title{
ERRATA
}

\section{Uso de espectroscopia de ultravioleta visivel (UV-VIS) para a detecção de quercetina em plantas por meio da formação do complexo quercetina-alumínio}

UV-Vis spectroscopy to detection of quercetin in plants by formation of quercetin-aluminum complex

Fabiele BERNARDI; Keller Paulo NICOLINI; Jaqueline NICOLINI Instituto Federal do Paraná - IFPR. Av. Bento Munhoz da Rocha, s/n, PRT280, Trevo da Codapar, CEP 85555-000. Palmas, PR, Brasil.

Ao rever o texto publicado como Nota Técnica em: Infarma, v.29, n.3, p.271-276, 2017, DOI.:10.14450/2318-9312.v29.e3.a2017.pp271-276

Observamos que há duas vezes no texto o termo:

"MeOH:AA 1:19 v/v " sendo o termo correto "AA:MeOH 1:19 v/v". 